\title{
The District Role in Building Capacity: Four Strategies
}

Diane Massell

Follow this and additional works at: https://repository.upenn.edu/cpre_policybriefs

Part of the Educational Administration and Supervision Commons, Educational Leadership Commons, Educational Methods Commons, Education Policy Commons, and the Teacher Education and Professional Development Commons

\section{Recommended Citation}

Massell, Diane. (2000). The District Role in Building Capacity: Four Strategies. CPRE Policy Briefs.

Retrieved from https://repository.upenn.edu/cpre_policybriefs/20

View on the CPRE website.

This paper is posted at ScholarlyCommons. https://repository.upenn.edu/cpre_policybriefs/20

For more information, please contact repository@pobox.upenn.edu. 


\title{
The District Role in Building Capacity: Four Strategies
}

\begin{abstract}
School districts strongly influence the strategic choices that schools make to improve teaching and learning. Districts-composed of local school boards, superintendents, and central office staff-act as gatekeepers for federal and state policy by translating, interpreting, supporting, or blocking actions on their schools' behalf. In fact, the efforts of districts to build the capacity of students, teachers, and schools are often the major, and sometimes only, source of external assistance that schools receive. In an effort to revisit the often forgotten role of districts in the improvement process, this policy brief explores the promises and challenges of four major capacity-building strategies that CPRE researchers observed in 22 districts in California, Colorado, Florida, Kentucky, Maryland, Michigan, Minnesota, and Texas over a two-year period.

\section{Disciplines}

Educational Administration and Supervision | Educational Leadership | Educational Methods | Education Policy | Teacher Education and Professional Development
\end{abstract}

\section{Comments}

View on the CPRE website. 


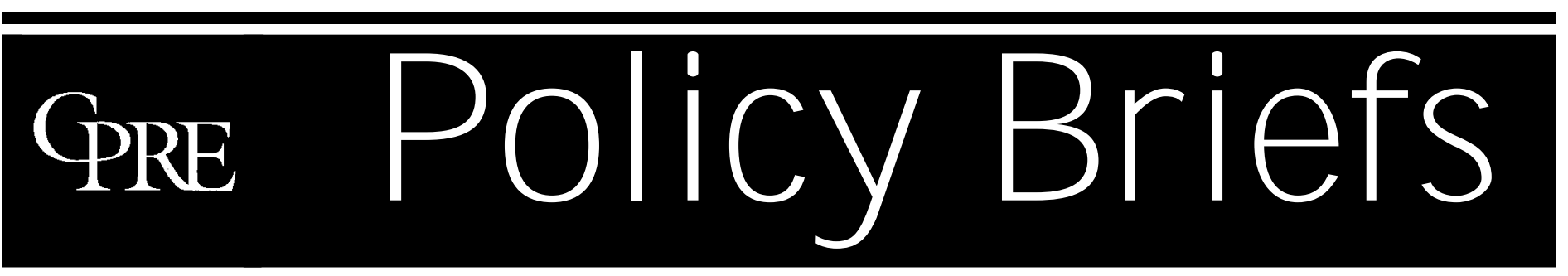

Reporting on issues in education reform

Graduate School of Education

- U niversity of Pennsylvania

- $\quad$ RB-32-September 2000

\section{The District Role in Building Capacity: Four Strategies}

\section{by Diane Massell}

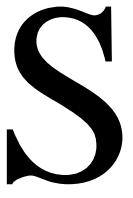

chool districts strongly influence the strategic choices that schools make to improve teaching and learning. Districts-composed of local school boards, superintendents, and central office staff-act as gatekeepers for federal and state policy by translating, interpreting, supporting, or blocking actions on their schools' behalf. In fact, the efforts of districts to build the capacity of students, teachers, and schools are often the major, and sometimes only, source of external assistance that schools receive. In an effort to revisit the often forgotten role of districts in the improvement process, this policy brief explores the promises and challenges of four major capacity-building strategies that CPRE researchers observed in 22 districts in California, Colorado, Florida, Kentucky, Maryland, Michigan, Minnesota, and Texas over a two-year period. These strategies include:

- Interpreting and using data;

- Building teacher knowledge and skills;
- Aligning curriculum and instruction;

- Targeting interventions on low-performing students and/ or schools.

These are not the only strategies the 22 districts used, but they are the ones that appeared most frequently. And, although the four strategies are prevalent in just about any district (all districts support some kind of professional development, for example), some embrace these activities in a more comprehensive way and use them as major mechanisms for enacting improvement. It is important to recognize that the strategies are not mutually exclusive; they can and do overlap in districts in ways that are often reinforcing of the single strategy which we separate out for purposes of discussion.

The project from which this brief results, "Education Reform Policy: From Congress to the Classroom," seeks to understand ways in which policies designed at different levels of the system support coherence, incentives for change, and

\footnotetext{
The Consortium for Policy Research in Education (CPRE) studies alternative approaches to education reform in order to determine how state and local policies can promote student learning. Currently, CPRE's work is focusing on accountability policies, efforts to build capacity at various levels within the education system, methods of allocating resources and compensating teachers, and governance changes like charters and mayoral takeover. The results of this research are shared with policymakers, educators, and other interested individuals and organizations in order to promote improvements in policy design and implementation. CPRE is supported by the National Institute on Educational Governance, Finance, Policymaking, and Management, Office of Educational Research and Improvement, U.S. Department of Education.
}

\section{CONSORTIUM FOR POUCY RESEARCH IN EDUCATION University of Pennsylvania • Harvard University • Stanford University University of Michigan - University of Wisconsin-Madison}


the capacity of the system to implement reform. This policy brief presents what was learned about how district policies build the capacity of schools and classrooms to improve.

\section{Four Major Capacity-Building Strategies}

\section{Data, Data, and More Data}

One of the most striking trends in nearly all 22 districts was a growing emphasis on the use of data to drive decisions about practice. "Data School District" is an example of an administration that has placed data and research at the core of their philosophy of change and improvement (See Sidebar 1).

While the use of data is clearly a major strategy in Data School District, the district is not unique in its interest in using information to focus and drive decision-making. Districts and schools are using performance and other data to plan professional development activities, to identify achievement gaps, to align curriculum and instruction, to assign and evaluate personnel, and to identify students for remedial or gifted and talented programs. All eight states in the study sample require or encourage some form of school improvement planning. While five of the states (Colorado, Florida, Kentucky, Maryland, and Texas) explicitly require schools to use outcome data in their improvement planning processes, all of the schools studied are doing it. Districts are playing an important role in helping them do so.

In the recent past, reporting of accountability data was often treated as a pro forma requirement, but now a majority of the districts in the study are taking more active roles in focusing attention on data and helping schools use them. Many of the districts are developing data expertise in their central offices and in the schools themselves. The Research and Evaluation staff from one Maryland district, for example, pro- vides analyses for schools. They hold day-long meetings with four-to-five school teams at a time, reviewing test results item-by-item, and looking at the number of students scoring at the different proficiency levels in each content area. They discuss the progress being made over time, what it means to have students achieving at different levels, and what the outcome scores mean. The district also works with individual schools and produces data profiles for them. A Colorado district is trying to help their schools develop in-house expertise. They require schools to identify at least one data analyst onsite, and provide them with training and pay for a three-year period.

When conversations about school improvement are driven by performance data, educators and district staff press for more and better data on student achievement. Districts and schools are administering commercial assessments or developing their own. A major purpose of these tests is to measure the continuous progress of students toward district and/ or state goals and to provide instructional feedback to teachers and schools. In addition, some districts want to provide data on individual students for special programs identification (e.g., special education). Districts also are interested in externally validating student performance, especially in basic skills areas, through the use of national, norm-referenced assessments. They use the test data to evaluate programs such as Title I and assess more rigorous standards, more grades, and more content areas (Goertz, Massell, and Chun, 1998).

\section{Building Teacher Knowledge and Skills}

Nearly all districts regard the building of teachers' knowledge and skills as a crucial component of change. Every district provides some form of support for professional training, whether it is by offering a menu of workshops or just providing the time, salary incentives, and resources for teachers and schools to pursue professional development. Some districts invest substantial resources and creative energy in pro-

\section{About CPRE Policy Briefs}

CPRE Policy Briefs are published by the Consortium for Policy Research in Education (CPRE). The research reported in this brief was conducted by CPRE. Funding for this work was provided by the U.S. Department of Education's National Institute on Educational Governance, Finance, Policymaking, and Management (Grant \#OERI-R308A60003), the Annie E. Casey Foundation, and the Pew Charitable Trusts. Opinions expressed in this brief are those of the author, and do not necessarily reflect the views of the National Institute on Educational Governance, Finance, Policymaking, and Management; the Office of Educational Research and Improvement; the U.S. Department of Education; the Pew Charitable Trusts; the Annie E. Casey Foundation; or the institutional partners of CPRE. 


\section{Sidebar 1 Data School District}

Data School District's faith in the power of data to bring about improvement is clearly reflected in the words of the district superintendent:

There has been a major change in the culture of the district. We are now a data-driven district. Data can be our best ally. It has not always been considered that way, but it is hard to dispute the data regarding student achievement. The data can be compiled in such a way to create a sense of urgency that I felt was necessary to bring about change.

Superintendent, Data School District

The superintendent and district staff doggedly focus on data and try to inculcate a stronger awareness of and use of research. For instance, a major responsibility of area superintendents is to make sure that schools understand and use state accountability data in their school improvement plans. Instructional guides are housed at each school to help them analyze and use data. Other central office staff, especially the testing division, provide significant support to schools on data interpretation. To develop professional norms about the importance of data, the superintendent annually visits every school in this large district to ask what they are learning from data and how they are using it. The district adopted basic standards for the selection of any new curriculum, requiring it to be research-based, standards-based, have an evaluation and professional development component, and have a bilingual component. The district offers schools a financial incentive $(\$ 50,000$ per school) to participate in a research-based New American Schools design.

fessional growth strategies. For example, "Learning Community School District" is trying to foster a norm of continuous learning and reflection for all of its staff, and is bringing together many elements to achieve this goal (see Sidebar 2 on page 4).

District strategies for building teachers' knowledge and skills vary along a number of dimensions including the time they allocate toward professional development, the incentives and support they provide teachers and schools for these activities, and the extent to which they focus professional development on a coherent philosophy of teaching. But one common theme across all of the study districts was a growing interest in the pursuit of less traditional formats for professional learning. Indeed, the literature on professional development is replete with criticisms about the most common format for staff training - the traditional "one-shot" workshop that lacks sustained follow-up support for teachers to apply new ideas in their classrooms (Little, 1993; National Commission on Teaching and America's Future, 1996). While menu-driven workshops are still prevalent in the study sample, districts are becoming more aware of their limitations. A Kentucky respondent, for example, acknowledged that despite a heavy financial investment in Different Ways of Knowing (DWOK) training, DWOK curriculum materials often lay unused because the professional development too often lacked "follow-up to see if it was effectively implemented, if it had an impact on the classroom." To address this problem, study districts are pursuing a number of non-traditional professional development formats such as teacher and school networks, peer mentoring programs, and professional development centers. However, the most frequently occurring alternatives found in the sample include school-based support, teacher leaders, and teacher participation in development.

School-based Support. A majority of the districts are creating professional development opportunities at the school site to provide follow-up and ongoing opportunities for professional learning. Customarily, central office staff or district designees - such as teachers on special assignment_rotate among a cluster of schools or are called upon on an as-needed basis to provide assistance in a building. The Kentucky district noted above, for instance, funds four resource teachers for its ten elementary schools. These teachers model lessons, mentor teachers in implementing new instructional programs and approaches like DWOK, and direct teachers to more information on new instructional practices.

Several districts have assigned staff full time to one school to provide continuous, on-site assistance. A Minnesota district is hiring a teacher facilitator on special assignment in each school to work one-on-one with staff on implementing the state's graduation standards. A Texas district assigns an instructional guide to each school to provide professional development in reading and mathematics, help prepare the school improvement plan, and help faculty interpret student achievement and other data generated by the state accountability system. A Maryland district created the role of Maryland State Performance Assessment Program teacher specialists and assigns one to each of its elementary and middle 


\section{Sidebar 2 Learning Community School District}

Learning Community School District turned some of its more traditional workshop formats into opportunities to build a coherent body of knowledge for teachers. Rather than the usual bundle of unrelated workshops, this district has a six-year plan for literacy and mathematics training related to its curricular vision. The first two years are mandatory for teachers and quite extensive. In literacy, for example, the district has developed a 30-hour Basic Literacy Training course centered on instructional content. In the second year, it requires mini-courses in such areas as phonics or reading comprehension. Offerings in subsequent years build on this base.

The district also supports less traditional formats for professional learning for teachers and administrators. Two of the three area superintendents in the district, for example, require their principals to conduct action research projects and collect data. The principals meet and discuss their research with the area superintendent and their peers, and are encouraged to do so with their own school staff. Some of the principals mirror these initiatives with their teachers. The district involves teachers in developing district standards, benchmarks, curriculum, new materials, assessments, and other initiatives. All schools have professional libraries and many have established study groups. The district is helping staff with emergency permits earn certification and is assisting new teachers. It is also in the process of developing teaching standards as well as mapping what administrators need to know that is related to standards-based academic content. To create an even more coherent set of professional development activities, the district has undertaken a comprehensive review of its professional development efforts.

schools. These specialists model performance-based instruction, help in planning, provide mini in-services to grade level teams, and assist teachers with new teaching strategies.

Teacher Leaders. A number of districts designate regularly assigned classroom teachers to provide information or support to their colleagues on specific innovations. For instance, while one Florida district provides week-long training workshops for all teachers in the University of Chicago School Mathematics Program, each of its schools also identifies two lead mathematics teachers to provide follow-up training for their co-workers during the year. A California district is beginning to train a cadre of teacher leaders elected by their peers on topics like the change process, how to promote professional development, and interpreting and using reading data.
They also will chair their school's professional development committees.

Teacher Participation in Development. Districts are enlisting teachers to create home-grown instructional policies and tools. Some of these activities, such as appointing teachers to textbook selection committees, are not new. But a number of the districts are going beyond these conventional activities and are using teachers to develop performance-based assessments, scoring rubrics, curriculum, and standards. Teachers in a Colorado district, for example, run a summer institute focused on the construction of curriculum units aligned to their local standards. These initiatives are seen not only as strategies for building the knowledge and skills of the teaching staff, but as ways for districts to expand their own capacity to accomplish major policy goals.

\section{Curriculum and Instruction}

Like the focus on teacher knowledge and skills, improving curriculum and instruction is seen as an essential element of capacity. In today's charged atmosphere of accountability and standards-based reform, districts are seeking to align their curriculum and instruction vertically to state policies and horizontally to other elements of district and school practice.

But how districts approach curricular and instructional changes and seek to achieve alignment varies substantially. Some districts take a technocratic approach that tightly and centrally engineers the elements of curriculum and instruction. For instance, "Curriculum Guidance School District" has a series of interconnected and explicitly detailed curriculum documents that are reinforced by district professional development workshops, a system of instructional oversight, and assessments (see Sidebar 3).

At the other end of the spectrum are districts that take a less structured, some might say more developmental, approach. Some districts try to foster alignment to common goals through professional development activities. The literacy and mathematics workshops in the Learning Community District, for instance, are not tied to particular textbooks or curriculum packages but to subject matter content more generally and a district curricular philosophy. Other districts develop much less detailed curriculum policies than Curriculum Guidance's. One Maryland district created an abbreviated set of outcomes linked to state standards in order to give its schools the flexibility it believes is essential for real change to occur. Some districts use performance assessments to align instructional practices and curriculum to new goals. A Colorado district, 
for instance, requires its teachers to administer classroomembedded assessments on the district's content standards, and teachers must score them using a district rubric. Eventually these assessments will be used as part of a package to certify whether a student has demonstrated proficiency on each content standard for high school graduation.

More often than not, however, curriculum guidance is a patchwork of loose and tight central control. Interestingly, this often varies by subject matter. The study districts typically exerted more technocratic central control over mathematics. For instance, one Michigan district uses an instructional method in language arts called Reading/Writing Workshop. There is no centrally adopted reading textbook; teachers have the funds and authority to select their own trade books. But the same district has adopted a textbook series in elementary mathematics because it saw a need for greater uniformity and continuity there. Indeed, other districts have implemented tighter central control over mathematics because they believe their elementary teachers are less comfortable with this subject. While decisions to exercise more centralized guidance may result from an evaluation of teachers' knowledge and skills, some districts in the sample consider other factors. In Kentucky, for example, schools have complete authority over curriculum and instruction by state law and schools often use different instructional materials. One district with a highly mobile student population found that this lack of consistency yielded significant problems in learning and school performance. They negotiated with the schools to identify a common set of textbooks to provide a more coherent curriculum for all students.

\section{Targeted Interventions: Schools and Students}

Another capacity-building strategy used by districts is to target additional resources and attention on poorly performing schools and students. Nearly one-third of the study districts provide support to schools identified as low-performing by state or local tests and accountability systems, although only two states-Florida and Maryland-require them to do so. Providing support for school improvement planning, such as is done in "Targeted Support School District" (see Sidebar 4 on page 6), is a common assistance strategy and often includes helping schools interpret and use performance data in planning. In a Michigan district, all unaccredited schools or schools with low interim accreditation receive help in data analysis from a cadre of state providers.

A number of the districts make extra staff and resources available to low-performing schools. Some create special

\section{Sidebar 3 Curriculum Guidance School District}

Curriculum Guidance School District launched a five-year plan to align its curriculum to state performance standards. Lengthy and highly specific curriculum guides provide standards, frameworks, and pacing sequences. They contain a hierarchy of outcomes that run the gamut from state to county to grade level and finally to unit outcomes, and identify lesson indicators or "essential learnings." They include resource guides for each grade level and planning guides for each unit outcome. The language arts guide, for example, shows teachers how they might allocate their time and contains a sample year-long planning matrix covering all the outcomes. It also contains periodic running records and mid-year assessments.

The district is aligning many other policy elements to these guides. It is developing assessments to track individual student progress against district outcomes (the state test does not provide reliable individual scores), and has adopted a textbook in mathematics. Professional development activities train principals and teachers in what instruction based on the curriculum guide should look like. Instructional use is monitored by a system of "look-fors."

offices, teams, or units to provide assistance. In one California district, schools in need of support receive coaches or special consultants, additional staff, and professional development for administrators, as well as support teams that include principals, teachers, and other staff from high-performing schools. Requiring or encouraging low-performing schools to network with more successful ones is intended to stimulate fresh thinking about how to improve performance. Some districts offer financial incentives for low-performing schools to adopt particular curriculum and instructional programs or whole school reforms. Several districts in Kentucky, Maryland, and Texas, for instance, encourage their low-performing schools to use Title I resources to institute some version of Reading Recovery.

Some districts (and states) accompany assistance with greater oversight and feedback. One California district requires its low-performing schools to engage in a self-study. A few districts, either informally or formally, reduce the authority of poorly performing schools and require or strongly encourage the use of particular instructional strategies or other interventions. And, under the aegis of state reconstitution laws or personnel evaluations, districts have removed principals from these schools. 


\section{Sidebar 4 Targeted Support School District}

Staff in the Targeted Support District give preference in terms of time and attention to schools identified as lowperforming under the state's accountability index. This attention extends to a set of "priority" schools identified by the district that could be classified as low performing under the state system the following year, since the state annually raises its performance requirements. A district intervention team spends about a half-day at each school visiting every classroom and focusing on four areas: school organization and management, culture and climate, curriculum and instruction, and parental involvement. They present their observations and recommendations to a school team, which then reports to the faculty to develop an improvement plan. The district follows up with ongoing technical assistance.

Finally, all of the study districts target special assistance to students who are not meeting local or state performance goals. Nine districts, for instance, use some version of Reading Recovery, an intensive tutoring program that offers alternative reading strategies for struggling young readers. There is a growing interest in retaining students who do not meet performance standards after interventions have been tried. Under Colorado legislation, districts must hold back third grade students in a lower reading group (note: not grade) if they do not meet performance goals. Four other districts in the sample currently, or plan to, retain students not meeting performance standards, and see it as a major component of their overall reform initiatives.

\section{Issues and Challenges}

There has been a strong tendency in recent federal and state policy initiatives to bypass or ignore the role of districts in the change process. Schools are the foci of accountability systems, and when they fail to meet performance standards they are increasingly subject to some form of reconstitution or other sanctions. However, districts remain the legal and fiscal agents that oversee and guide schools. In many ways, districts are the major source of capacity-building for schoolsstructuring, providing, and controlling access to professional development, curriculum and instructional ideas, more and more qualified staff, relationships with external agents, and so on. What districts do influences how schools as organizations address the performance goals set by states, and whether or not they have the necessary capacity to do so. Policymakers should attend to the strategies districts use to influence schools, and the effects of these strategies on schools' capacity. This brief has highlighted four distinct district approaches to school improvement: the use of data to provide feedback and plan change, the creation of new professional development strategies, the alignment of curricula and instruction, and the targeting of assistance to low-performing schools and students. But there are challenges in successfully implementing these strategies.

Using Data. Expectations about the use of data to improve decision-making are high and, as mentioned, districts are devoting a lot of attention to interpreting and analyzing data for school improvement purposes. However, going from "here is how our students are performing on these items" to "here is what we have to do about it" requires additional knowledge. One of the greatest needs identified by respondents is helping teachers and administrators better understand how to use data to improve their performance. In the words of one respondent:

One of our biggest challenges right now in the district, I think, is to help schools look at student achievement indicators and try and connect them back to what they are doing, what aren't they doing, you know, to really help them understand how to look at data, how to look at student work, how to interpret. We have sent schools multitudes of pages of data over the years, but we have [not] . . . done a very good job ... in helping them understand what to do with it when they got it.

Many respondents talked about the difficulty of helping schools and teachers move from a focus on test-taking skills to integrating standards and the philosophies of reform into their instructional core. For instance, teachers often view testing as a burden rather than as an integral part of instruction in spite of the intentions of designers of new tests with performance-based tasks. Said one Texas respondent:

We are hoping the schools see the connection [between the accountability system and curriculum.] ... The goal of training is to help people properly understand that TAAS is an assessment of a good language arts program, it is not just a test. We are hoping that they understand good instruction and not just TAAS practice will lead to improved scores. One of our big goals is to get people to stop teaching TAAS and to start teaching writing and reading.

Similarly, district administrators in one Kentucky site are concerned that teachers see improving test scores as a simple 
matter of curricular alignment, rather than using data to seriously analyze their own instructional strategies.

Another challenge relates to the difficulty which teachers, schools, and districts have in managing and using what has often become an overwhelming amount of data. As noted above, districts and schools frequently administer their own assessments and collect other kinds of information on schools and programs in addition to state accountability data. Many of these tests evaluate different skills, are scored using different standards and procedures, and are not well correlated to one another. The burden falls on teachers, schools, and districts to compile this information and ascertain how it sheds light on curriculum, teaching, management, and other schooling practices.

Focusing Professional Development. Coordinating professional development activities, making them coherent to reinforce common goals, and ensuring their quality are also major issues for districts. Even districts like Learning Community, which focuses tremendous energy on developing a coherent and comprehensive professional development strategy, found it necessary to evaluate and reassess their initiatives to improve this process. Part of the problem is that professional development dollars are fragmented into different funding streams and, in large districts, different corners of district bureaucracies. These corners have different priorities. Communication and "turf" issues make creating coherent and mutually reinforcing systems of professional development in these situations difficult. Since many teachers independently select which experiences they will participate in, tying their decisions to the needs of the school or district as a whole is another challenge to coherence.

Another issue emerges as a result of high teacher turnover and shortages in qualified staff, particularly in urban areas. The knowledge and skills needed for staff is very different from the professional development that a more seasoned and more stable workforce needs. Many districts and schools have stretched budgets, and providing regular basic training courses and systems of support for new or uncertified teachers along with the more sophisticated activities that experienced teachers would prefer is a serious challenge.

These are just some of the issues and challenges that districts face in building capacity for improvement but there are many others. For instance, most districts find that they do not have the staffing levels they need to support the kinds of academic reforms called for by standards-based reform. One Maryland district, for example, has experienced sharp cut- backs in its curriculum staff over the years. Providing alternative forms of professional learning opportunities also requires more extensive and intensive efforts, and again districts frequently do not have sufficient staff to carry out these visions quickly and easily. To continue to move forward with educational improvement, these and other challenges will have to be effectively addressed.

\section{References}

Goertz, M. E., Massell, D., and Chun, T. (1998) "District Response to State Accountability Systems." Paper presented at the Annual Meeting of the Association for Public Policy Analysis and Management, New York, NY.

Little, J. W. (1993). “Teachers' Professional Development in a Climate of Educational Reform." Educational Evaluation and Policy Analysis, 15(3), 129-151.

National Commission on Teaching and America's Future (1996). What Matters Most: Teaching for America's Future. Report of the National Commission on Teaching and America's Future. New York: Author.

\section{About the Author}

Diane Massell is a Senior Research Associate with CPRE at the University of Michigan. She is co-principal investigator of CPRE's study of education reform policy. Other recent work includes research on the process and politics of developing new content standards, and state and local policy factors influencing the use of alternative assessment.

\section{Acknowledgments}

The author would like to thank the members of the research team for their high-quality cases, analytic insights, and challenging comments. They are: Margaret Goertz and Mark Duffy of the University of Pennsylvania; Robert Floden and Suzanne Wilson of Michigan State University; Tammi Chun of RAND; Catherine Clark, Kay Thomas, and Kerri Briggs of the Texas Center for Educational Research; Carolyn Herrington of Florida State University; Jane Clark Lindle of the University of Kentucky; Joe Petrosko of the University of Louisville; and Pat Seppanon and Laura Bloomberg of the University of Minnesota. 


\section{About CPRE}

The Consortium for Policy Research in Education (CPRE) unites five of the nation's leading research institutions to improve elementary and secondary education through research on policy, finance, school reform, and school governance. Members of CPRE are the University of Pennsylvania, Harvard University, Stanford University, the University of Michigan, and the University of Wisconsin-Madison.

CPRE conducts research on issues such as:

- education reform

- student and teacher standards

- state and local policymaking

- education governance

- accountability

- school finance

- teacher compensation

- student incentives

\section{Nondiscrimination Statement}

The University of Pennsylvania values diversity and seeks talented students, faculty, and staff from diverse backgrounds. The University of Pennsylvania does not discriminate on the basis of race, sex, sexual orientation, religion, color, national or ethnic origin, age, disability, or status as a Vietnam Era Veteran or disabled veteran in the administration of educational policies, programs, or activities; admissions policies, scholarships, or loan awards; and athletic or University administered programs or employment. Questions or complaints regarding this policy should be directed to Executive Director, Office of Affirmative Action, 1133 Blockley Hall, Philadelphia, PA 19104-6021 or (215) 898-6993 (Voice) or (215) 898-7803 (TDD).

To learn more about CPRE research or publications, please call (215) 573-0700.

World Wide Web:

www.upenn.edu/gse/cpre/

www.wcer.wisc.edu/cpre/

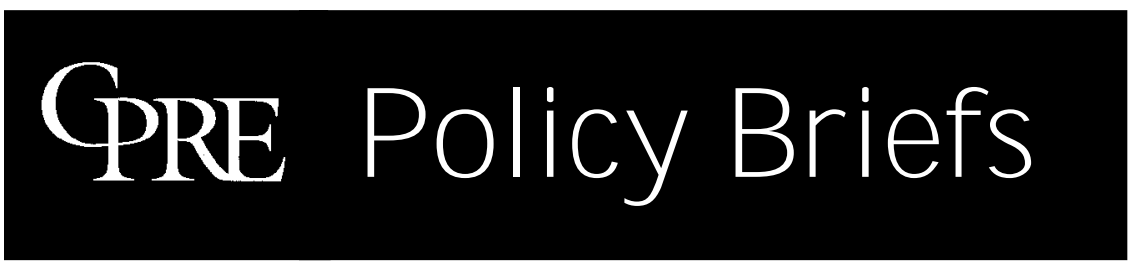

NON PRO FIT

U.S. POSTAGE

PAID

PERM IT N O . 2563

PHILADELPHIA, PA

Graduate School of Education

University of Pennsylvania

3440 Market Street, Suite 560

Philadelphia, PA 19104-3325 